\title{
Educação Musical no Ensino Médio: \\ alguns apontamentos
}

Luciana Del-Ben

(Universidade Federal do Rio Grande do Sul)

RESUMO: Este artigo tem como foco a educação musical no ensino médio. Configurase a partir de uma justaposição de resultados de pesquisa e de ideias de diferentes autores, que tratam dos jovens e suas relações com a música e com a escola e dos desafios da escola na sociedade atual. Busca, assim, contribuir para subsidiar reflexões e ações em direção à construção de uma escola para, e com, os jovens, e, nela, de uma educação musical que atenda aos anseios, necessidades e interesses desses jovens.

PALAVRAS-CHAVE: educação musical no ensino médio; jovens e escola; escola.

\section{MUSIC EDUCATION IN HIGH SCHOOL: SOME REMARKS.}

ABSTRACT: This paper focuses on music education in secondary schools. It is set up from a juxtaposition of research results and ideas from different authors that refer to young people and their relationships with music and with the school, as well as to the challenges of schooling in the contemporary society. These results and ideas can function as a basis to reflecting and acting towards building a school for, and with, young people, and, within the school, practices of music education that can meet the aspirations, needs and interests of young people.

KEYWORDS: Music education in secondary schools; Young people and school; school. 
Desde a aprovação da Lei $n^{0 .}$ 11.769, em 18 de agosto de 2008 (Brasil, 2008), tem sido significativa a mobilização de formadores, pesquisadores e professores da área de educação musical no sentido de garantir a presença da música nas escolas e, mais que isso, a institucionalização do ensino de música na educação básica. Dentre as etapas da educação básica, o ensino médio, como pretendo demostrar a seguir, parece ser a que mais nos desafia nesse processo, e é essa etapa que focalizo no presente artigo.

Tratar da educação musical no ensino médio nos exige pensar, de um lado, sobre os jovens e suas relações tanto com a música quanto com a escola e, de outro, sobre a escola que queremos e que podemos construir para esses jovens. Este trabalho, de um caráter que se poderia chamar pré-ensaístico, configura-se a partir de uma colagem ou justaposição de resultados de pesquisa e de ideias de diferentes autores, na tentativa de abarcar esses "lados", tendo em vista o objetivo de apresentar alguns apontamentos que poderão orientar nossa reflexão sobre a educação musical no ensino médio e também nossas ações ${ }^{1}$.

Acredito que os estudos e pesquisas que vêm sendo realizados pela área de educação musical têm nos ajudado a conhecer cada vez mais e melhor a relação dos jovens com a música - jovens que, na escola, passam a ser tratados como alunos ou estudantes (ou também como alunos ou estudantes). E, por meio dessa relação, também temos compreendido melhor os jovens. Dentre os trabalhos realizados, destaco, pela regularidade e pela constante revisitação, aqueles realizados por Margarete Arroyo $(2007,2009)$ e por Jusamara Souza e seu grupo de pesquisa (2000; 2008). Não retomarei, aqui, essa literatura, mas gostaria de ressaltar algumas das conclusões e dos avanços que ela vem trazendo para a área de educação musical, tais como: a constatação, hoje já de senso

\footnotetext{
${ }^{1}$ A escolha da palavra apontamentos, no objetivo e no título deste artigo, foi inspirada pelo texto do educador português António Nóvoa 2011, sem a pretensão, no entanto, de alcançar o brilhantismo e a profundidade desse autor. Os apontamentos, aqui, devem ser entendidos no seu sentido mais ordinário: anotações ou notas que se registram durante leituras, para aproveitamento posterior ou como trabalho preliminar para a elaboração de um texto. Isso justificaria o caráter pré-ensaístico atribuído ao artigo.
} 
comum, da forte presença da música na vida dos jovens; o entendimento de que essa presença se concretiza por meio de práticas musicais diversas e por diferentes modos de se relacionar com música, não só porque são muitas as músicas, mas, também, porque não se pode falar em jovem ou juventude, mas em jovens/juventudes - no plural - e suas culturas juvenis; a multiplicidade de dimensões presentes nas experiências musicais dos jovens, que incluem, entre outras, relações de gênero, classe, etnia e religião, muito além dos aspectos sonoro-musicais; a diversidade de significados atribuídos a essas experiências; e, principalmente, a força da música na construção das identidades dos jovens.

Esses trabalhos vêm nos ensinando quão complexa e diversa é a relação dos jovens com a música. Essa complexidade e diversidade não são exclusivas dos jovens, mas, talvez, seja entre eles que elas se tornem mais visíveis. E é também entre os jovens que a escola parece mais facilmente perder o sentido. Por isso, os resultados e conclusões dos trabalhos da área de educação musical, muitas vezes, vêm aliados a uma crítica à escola, que não tem conseguido se constituir como uma escola jovem, para os jovens. Como observa Arroyo (2007, p. 33): “Aquele adolescente e jovem totalmente submisso aos adultos e à escola deu lugar a uma juventude que tem imposto seus modos de ser, suas necessidades e desejos. Para dar conta dessa nova maneira de ser da juventude, a escola deve mudar".

Foi essa necessidade de mudança que motivou a reforma do ensino médio na década de 1990. Para Dagmar Zibas (2005, p. 24-25), pesquisadora da área de educação, "o contexto da virada do século justificava (e ainda justifica) um profundo repensar do currículo do ensino médio, em vista, principalmente":

- da "explosão da demanda por matrículas", isto é, maior democratização do acesso e, consequentemente, maior heterogeneidade do alunado ( $p$. 25);

- dos "requisitos do novo contexto produtivo", impondo "a necessidade de formação dos jovens com base em novos conhecimentos e competências" (p. 25);

- da "exigência de desenvolvimento de conhecimentos e valores para a construção de uma cidadania democrática”, exigindo da escola que “ensine a 'leitura desse mundo'” (p. 25); 
- e, por fim, da "exigência de aproximação entre currículo e cultura juvenil" (p. 25).

Passados mais de 10 anos da publicação das Diretrizes Curriculares Nacionais para o Ensino Médio, em 1998, Acácia Kuenzer, também da área da educação, conclui, em artigo publicado no final de 2010, que "a década [de 2000] foi perdida para o ensino médio" (Kuenzer, 2010, p. 861), já que a reforma pretendida não foi alcançada.

De modo semelhante, em artigo publicado em 2007, Juarez Dayrell, pesquisador da educação frequentemente citado nos estudos da educação musical, afirmava que:

apesar de várias iniciativas do poder público, não houve ainda uma adequação da estrutura escolar a esta nova realidade. Salvo algumas exceções, principalmente no âmbito das redes de ensino municipais de algumas cidades brasileiras, a estrutura da escola pública, incluindo a própria infraestrutura oferecida, e os projetos político-pedagógicos ainda dominantes em grande parte das escolas não respondem aos desafios que estão postos para a educação dessa parcela da juventude. Se a escola se abriu para receber um novo público, ela ainda não se redefiniu internamente, não se reestruturou a ponto de criar pontos de diálogo com os sujeitos e sua realidade. (Dayrell, 2007, p. 1116-1117).

E mais: segundo o autor, "tem sido reiterada a crítica dos alunos a um currículo distante da sua realidade, demandando que os professores os 'situem na matéria', ou seja, os ajudem a perceber o que determinado conteúdo tem a ver com eles e sua vida cotidiana" (Dayrell, 2007, p. 1122).

Essas críticas à escola - de modo geral - são, muitas vezes, automaticamente transpostas para o ensino de música, isto é, para as experiências de aprendizagem em/de/com música que a escola intencionalmente organiza para os jovens estudantes, experiências que se constroem em torno dos saberes e das relações sociais (ver Moreira; Candau, 2007).

Apesar das críticas existirem, como vários autores vêm ressaltando, ainda são poucos os estudos e pesquisas sobre o ensino de música no ensino médio. Em levantamento que realizei dos trabalhos publicados na Revista da Abem (Associação Brasileira de educação Musical), com o objetivo de analisar as 
principais tendências de investigação de trabalhos que tomam a educação musical escolar como objeto de estudo (Del-Ben, 2011), pude constatar que, dos 217 artigos publicados nos vinte números do periódico entre os anos de 2000 e 2010 , 81 deles, número correspondente a $37,3 \%$ da produção total, tomam a educação musical escolar como objeto de estudo, de modo central ou periférico.

A análise dos elementos pré-textuais desses 81 trabalhos indica que, em relação ao nível de ensino focalizado, os dados são pouco precisos. Há trabalhos que se referem simultaneamente à escola e a outros espaços educativos, como escolas de música, projetos sociais e, de modo mais indefinido, espaços "fora da escola"; e outros que não especificam qualquer nível de ensino, apresentando termos como escola pública, escola regular ou contexto escolar. Somente 58 (71,6\%) dos 81 artigos analisados explicitam o nível de ensino a que se referem em seus elementos pré-textuais. O ensino fundamental é o nível mencionado com maior frequência, principalmente os anos iniciais. O ensino médio é explicitamente citado somente em oito trabalhos, embora sempre associado a outros níveis. Embora considerações mais precisas dependam da leitura dos artigos na íntegra, os dados contidos nos elementos pré-textuais parecem sinalizar que as especificidades das diferentes etapas da escolarização na educação básica, especialmente as do ensino médio, não têm sido suficientemente tematizadas pela área de educação musical (Del-Ben, 2011).

Também são raras, nesses trabalhos, as vozes dos alunos. Os elementos pré-textuais sinalizam que a educação musical escolar tem sido investigada principalmente a partir da perspectiva dos saberes escolares e dos professores, campos que são abordados, respectivamente, em 55,6\% e 44,4\% do total de 81 trabalhos analisados. A perspectiva dos alunos está presente, de diferentes modos, somente em 18,5\% dos trabalhos (Del-Ben, 2011).

Isso nos dificulta construir um diagnóstico amplo sobre a educação musical no ensino médio. Um dos trabalhos que busca esse diagnóstico é a dissertação de mestrado de Cristina Bertoni dos Santos, defendida em 2009, que, segundo a autora, constitui-se "como uma primeira aproximação" às "relações de alunos do ensino médio com a aula de música da escola"(Santos, 2009, p. 10). 
A dissertação teve como objetivo geral “compreender as relações que permeiam as concepções e expectativas de alunos do Ensino Médio a respeito da aula de música na escola". Os objetivos específicos procuraram examinar "as concepções [dos alunos] e os significados [por eles] atribuídos à escola e à aula de um modo geral, à música, aos processos de ensino e aprendizagem em música, e à aula de música da escola" (Santos, 2009, p. 9). Os dados foram coletados por meio de grupos de discussão, com 31 estudantes do $1^{\circ}$ ano do ensino médio de uma escola estadual de Porto Alegre/RS. Parte dos resultados da dissertação foi recentemente publicada (Santos, 2012). Para contribuir com a reflexão proposta neste artigo, apresento algumas falas dos alunos investigados por Santos (2009), falas que, embora deslocadas do contexto em que foram elaboradas ${ }^{2}$, nos mostram o que esses estudantes pensam e esperam da escola, do professor e da aula de música e suas ideias de educação musical escolar no ensino médio.

\section{- Sobre os sentidos da escola:}

Pra trabalhar, pra arrumar emprego, pra não ser empacotador. Ah, porque sem estudar é difícil conseguir um bom emprego. Ter um trabalho bom.

Sem a escola, não consegue arranjar um trabalho, bom trabalho. (Santos, 2009, p. 54)

\section{- Sobre as aprendizagens escolares: $A$ escola e o futuro}

Assim, ó! No fim, talvez nem leve pra vida, o cara aprende física, matemática, aí, no fim, consegue emprego no mercado como empacotador.

Pra varrer rua, não precisa ter estudo (Santos, 2009, p. 56)

\section{A escola como lugar de convívio}

A convivência e ter que aturar certas coisas.

Respeitar.

Trabalhar em grupo. (Santos, 2009, p. 57)

Pra te ensinar a viver em grupo.

Estar integrado, assim, com a turma. Conviver com outras pessoas, né, sora? Ser mais sociável.

Porque a escola educa o indivíduo para a sociedade, né, pra viver assim. (Santos, 2009, p. 57)

Respeitar as pessoas com que quem tu convive normalmente.

\footnotetext{
2 Para dar mais fluência à leitura, foram excluídos os nomes dos alunos e os números dos grupos de discussão.
} 
Convivência, educação.

Ah, respeito, assim.

Conhecer novos amigos, conviver com as pessoas.

Sim, eu vejo a cara deles todo o dia, como é que eu não vou respeitar? (Santos, 2009, p. 57)

Conhecer novos amigos, conviver com as pessoas.

Aprende a conviver, ter diálogo, porque se não, não dá.

Aprende a se comunicar. (Santos, 2009, p. 57)

\section{- Sobre o professor e as relações entre alunos e professor}

$\mathrm{O}$ professor tem que saber ensinar. Tem professores que passam as coisas e deu, não explicam. (Santos, 2009, p. 65)

E tem uns que falam tanto, preferem mais falar do que nós, nem perguntam, só querem falar, falar, falar.

É um saco. Se todos estivessem falando, daí [o professor] vai saber quem aprende e quem não aprende.

Começam a falar, falar, e aí acaba a aula e eles ficam falando, não dá!

E na próxima aula repetem tudo de novo.

Tem uns que te deixam tonto, preferem mais falar que nós, né? Nem perguntam. (Santos, 2009, p. 66)

Alguém tem que te ajudar, tem que fazer tu sentir vontade.

Tinha que ter mais diálogo.

Tem que ter mais diálogo, senão a coisa não anda.

Perguntar, conversar. Todos falar, não só ele falar.

Qualquer coisa, sora! Uma redação. (Santos, 2009, p. 68)

Nessa fase da adolescência, a gente tá construindo, né, sora, nossa personalidade ainda. (Santos, 2009, p. 68)

\section{- Sobre as expectativas em relação à aula de música:}

\section{$A$ aula de música como lugar de aprendizagens musicais}

Mais aula prática.

Aula mais variada.

Assim como a senhora tá ensinando a flauta e aí, depois que a senhora ensinar a flauta, especifica em outra coisa.

Ensinar a cantar também.

Cantar, não.

Eu entrei na aula de música porque eu queria aprender a tocar bateria, também porque eu acho legal.

Eu queria tocar guitarra.

Eu queria aprender a tocar violão.

Um pouco de cada coisa, mas mais teclado, eu acho. Eu já fiz aula de teclado.

É, tipo, a música tá ali, mas eu não sei escutar ela, [na aula de música] tu vai saber mais sobre ela. Uma coisa é tu achar ela legal e tu não saber o que é escutar o sentido, tu ter noção dela, acompanhar no ritmo certo. (Santos, 2009, p. 93)

Eu quero aprender as pauta lá, ó. A pauta musical, que eu não sei. Que o meu pai tem um livro cheio de pauta e ele não me ensina também, ele fica brabo. (Santos, 2009, p. 94)

Música, na teoria, eu também não tenho. 
Tipo, eu sei trabalhar em clave de sol, mas tem outras, clave de dó que tem, né? (Santos, 2009, p. 94)

\section{A aula de música como espaço de convívio e respeito}

A aula de música, eu acho tri, porque tu aprende a lidar com o gosto dos outros. (Santos, 2009, p. 95)

A gente aprende a conviver com as diferenças, assim.

Com todos os estilos.

Tem que conviver com a [muda a frase]. Porque música é a vida, né? A gente tem que conviver com todos os estilos de música. (Santos, 2009, p. 95)

Acredito que essas falas nos incitam a refletir sobre como temos concebido o ato de ensinar, a relação do professor com os alunos e, de modo mais amplo, os sentidos da própria escola, o que inclui os sentidos de aprender/ensinar música na escola.

Os alunos deixam claro que ensinar não é mera transmissão de conteúdos, embora seja ação que não se realize sem conteúdos nem sem algum tipo de transmissão. Parece que, para eles, como definem as argentinas Laura Basabe e Estela Colls, "ensinar é uma ação orientada a outros e realizada com o outro", o que implica um processo de comunicação e, também, dedicação, zelo, cuidado em relação ao aluno, "uma preocupação pela pessoa do aluno e pelo que ele pode chegar a ser" (Basabe; Colls, 2010, p. 144, p. 146, tradução minha). Elas prosseguem: "O ensino envolve, pois, um encontro humano. Porque ensinar é, em definitivo, participar no processo de formação de outra pessoa, tarefa que só pode ser feita em um sentido pleno com esse outro" (Basabe; Colls, 2010, p. 146, grifo das autoras, tradução minha).

Parece ser nesse sentido que o parecer do Conselho Nacional de Educação/Câmara de Educação Básica sobre as Diretrizes Curriculares Nacionais Gerais para a Educação Básica, aprovado em 07 de abril de 2010, sustenta que:

O professor da educação Infantil e dos anos iniciais do Ensino Fundamental é, ou deveria ser, um especialista em infância; os professores dos anos finais do Ensino Fundamental e do Ensino Médio, conforme vem defendendo Miguel Arroyo (2000), devem ser especialistas em adolescência e juventude, isto é, condutores e educadores responsáveis, em sentido mais amplo, por esses sujeitos e pela qualidade de sua relação com o mundo. (Brasil, CNE/CEB, 2010, p. 54-55). 
Pensar nas pessoas não significa abrir mão dos conhecimentos que caracterizam os componentes curriculares, incluindo a música, pois, como também consta no parecer, além de conhecer a escola, sua organização, funcionamento e finalidades, "o professor precisa, particularmente, saber orientar, avaliar e elaborar propostas, isto é, interpretar e reconstruir o conhecimento" (Brasil, CNE/CEB, 2010, p. 54). Os jovens alunos do ensino médio investigados por Santos (2009) parecem desejar uma escola que seja capaz de acolher seus interesses, necessidades, valores e saberes, mas que, ao mesmo tempo, também seja capaz de ampliar esses saberes.

António Nóvoa, no texto intitulado "A escola e a cidadania apontamentos incômodos" - nos convida a pensar sobre essa complexa relação que acontece na escola entre pessoas - em formação e formadoras - e entre pessoas e saberes. Ele assim escreve:

Resumindo de maneira excessivamente simples a história do último século, podemos dizer que a Escola se foi desenvolvendo por acumulação de missões e conteúdos, numa espécie de constante transbordamento, que a levou a assumir uma infinidade de tarefas.

Começou pela instrução, mas foi juntando a educação, a formação, o desenvolvimento pessoal e moral, a educação para a cidadania e para os valores...

Começou pelo cérebro, mas prolongou a sua acção ao corpo, à alma, aos sentimentos, às emoções, aos comportamentos...

Começou pelas disciplinas, mas foi abrangendo a educação para a saúde e para a sexualidade, para a prevenção do tabagismo e da toxicodependência, para a defesa do ambiente e do patrimônio, para a prevenção rodoviária...

Começou por um "currículo mínimo", mas foi integrando todos os conteúdos possíveis e imaginários, e todas as competências, tecnológicas e outras, pondo no "saco curricular" cada vez mais coisas e nada dele retirando.... (Nóvoa, 2011, p. 2)

Essa "evolução" - caricaturada, conforme o autor - "deu-se no quadro de uma imagem da Escola como instituição de regeneração, de salvação e de reparação da sociedade". E "grande parte dos discursos sobre a cidadania (...) sustentam-se nesta alargada e abrangente concepção de formação escolar" (Nóvoa, 2011, p. 2). 
A partir dessa caracterização, Nóvoa reflete sobre o futuro da escola, e propõe que ela seja concebida não mais como “'reparadora' da sociedade”, como "uma escola transbordante" e utópica, "que procura compensar as "deficiências da sociedade', chamando a si todas as missões possíveis e imagináveis"; mas como uma “organização centrada na aprendizagem” (Nóvoa, 2011, p. 8 - grifos do autor).

O cenário da escola como "organização centrada na aprendizagem"

sugere uma valorização da arte, da ciência e da cultura, enquanto elementos centrais de uma 'sociedade do conhecimento'. Esta perspectiva sustenta-se em três argumentos principais: primeiro - nas sociedades do conhecimento, mais ainda do que nas sociedades industriais, o pior que podemos fazer às crianças [o que podemos estender aos jovens], sobretudo às crianças dos meios mais pobres, é deixá-las sair da escola sem uma verdadeira aprendizagem; segundo - ao olhar para muitos países, percebe-se o crescimento de uma 'escola a duas velocidades', isto é, de uma escola centrada na aprendizagem para os ricos e no acolhimento social para os pobres; terceiro - hoje, os novos conceitos de aprendizagem envolvem, para além dos conhecimentos, as emoções, os sentimentos e a consciência, implicam o método, o estudo e a organização do trabalho, incluem a criatividade, a capacidade de resolver problemas, a inteligência e a intuição. (Nóvoa, 2011, p. 8)

Para Nóvoa (2011, p. 9), “se a modernidade escolar se definiu por transbordamento, a contemporaneidade escolar se definirá por retraimento". Esse retraimento, entretanto, só será, de fato, possível se outros lugares da sociedade se comprometerem e responsabilizarem por parte das tarefas hoje atribuídas à escola e aos processos de escolarização (Nóvoa 2011, p. 10). E é o retraimento que permitirá à escola cumprir suas duas principais finalidades: "por um lado, a transmissão e apropriação dos conhecimentos e da cultura; por outro lado, a compreensão da arte do encontro, da comunicação e da vida em conjunto" (Nóvoa, 2011, p. 9). Para o autor, é isto que a escola sabe fazer e é o que ela faz melhor. Por isso:

É nisto que ela deve concentrar as suas prioridades, sabendo que nada nos torna mais livres do que dominar a ciência e a cultura, sabendo que não há diálogo nem compreensão do outro sem o treino da leitura, da escrita, da comunicação, sabendo que a cidadania se conquista, desde logo, na 
aquisição dos instrumentos de conhecimento e de cultura que nos permitam exercê-la. (Nóvoa, 2011, p. 9)

Numa direção semelhante, González e Fensterseifer (2009, p. 21) defendem que uma das funções da escola é “introduzir os alunos no mundo sociocultural que a humanidade tem construído, com o objetivo de que eles possam incluir-se no projeto, sempre renovado, da reconstrução desse mundo". Cumprir essa função, se concordarmos com ela, nos exige refletir sobre quais seriam as formas "mais defensáveis" de representar o mundo e de conviver socialmente, e também sobre o valor das "maneiras de validar essas formas de conhecer e conviver" construídas pela humanidade (González e Fensterseifer, 2009, p. 21).

Obviamente, não há receitas ou um único caminho a seguir para que consigamos construir, se assim desejarmos, uma escola menos rígida e mais humana para os jovens, e que, ao mesmo tempo, valorize as construções humanas, como a arte, a ciência e a cultura, como "elementos centrais de uma 'sociedade do conhecimento'" (Nóvoa, 2011, p. 8). Definir como poderiam se configurar esses elementos centrais é tarefa bastante desafiadora, porque muitas podem ser as respostas, já que vinculadas a contextos e situações específicas. A massificação da escola e a democratização das oportunidades de educação transformaram de modo significativo os perfis dos estudantes que hoje frequentam a escola, o que nos demandou, e continua a demandar, rever e reconstruir nossos modos de pensar o ensino e de ensinar. Além disso, num mundo que se transforma constantemente, em função da vertiginosa produção e difusão de conhecimentos (científicos, tecnológicos, artísticos e filosóficos), nossas referências acabam por se tornar menos estáveis, embora continuem a ser referências.

O contexto da sociedade contemporânea parece tornar mais difícil a busca de respostas ou caminhos. Alguns princípios, no entanto, podem nos ajudar a construí-los. E é nesse sentido, então, que, para finalizar este artigo, apresento ideias de um artigo de Inés Dussel, pesquisadora argentina da área de educação. Dussel apresenta um conjunto de critérios para a construção de uma “cultura 
comum na escola", isto é, um "núcleo de referências comuns que permit[a] ao aluno se integrar à sociedade nacional e se converter em cidadão" (Dussel, 2009 . p. 351).

Primeiramente, a autora defende a necessidade de fazer da escola um lugar para o encontro/confronto com a alteridade; um "lugar capaz de nos por em contato com um mundo-outro, (...) o mundo-outro que nos confronta com o desconhecido, o que nos permite entender e desafiar nossos limites e nos faz mais abertos aos outros e a nós mesmos" (Dussel, 2009, p. 359). Não se trata, portanto, de simplesmente transmitir uma tradição, mas de reescrevê-la, renová-la e redefini-la com as novas gerações.

A escola deve, ainda, "sustentar-se na gratuidade do dom", gratuidade que é entendida em múltiplos sentidos:

porque é acessível a todos que queiram, mas sobretudo porque não exige ou promete que esse conhecimento vá ser utilitário, mas que servirá (...) para outros tempos, para tempos que não têm forma no calendário social e sim no humano, o tempo de cada um. Além disso, a escola deve oferecer tempo, paciência, lentidão, silêncio, a possibilidade da dúvida (...) um contexto onde se possa repousar "no outro", numa herança acumulada, num saber que o outro nos oferece, num espaço onde se possa errar e voltar a provar sem maiores consequências. (Dussel, 2009, p. 360)

A escola deve, também, "dar mais chaves para decifrar a experiência comum, cada vez mais opaca em sua fragmentação e em sua velocidade de renovação" (Dussel, 2009, p. 360). Para tanto, deve continuar recorrendo às disciplinas escolares, mas também deve se abrir a novos temas, como os meios de comunicação e as tecnologias, tão presentes na vida dos jovens e que tanto têm transformado nossas referências e nossos modos de pensar, sentir e agir.

Por fim, Dussel (2009) destaca a importância de a escola “encontrar um modo de afirmação da transmissão cultural que não parta de um gesto amargo e desencantado” (p. 361). E recomenda: “a escola, essa depositária do passado que se encontra com o futuro nos jovens, deve evitar a nostalgia e sobretudo a amargura por não ser mais o centro das referências culturais" (p. 362). 
Espero que os apontamentos aqui apresentados possam contribuir para nossas reflexões e ações no cenário atual, em direção à construção de uma escola jovem, para, e com, os jovens, e, nela, de uma educação musical sem nostalgia e amargura, que atenda aos anseios, necessidades e interesses desses jovens.

\section{Referências}

ARROYO, Margarete. Escola, juventude e música: tensões, possibilidades e paradoxos. Em Pauta, v. 18, n. 30, p. 5-39, jun. 2007.

ARROYO, Margarete. Juventudes, músicas e escolas: análise de pesquisas e indicações para a área da educação musical. Revista da ABEM, n. 21, p. 53-66, mar. 2009.

BASABE, Laura; COLLS, Estela. La enseñanza. In: CAMILLONI, Alicia. (Org.). El saber didáctico. Buenos Aires: Paidós, 2010. p. 125-161.

BRASIL. Conselho Nacional de Educação. Câmara de educação Básica. Parecer CNE/CEB No: 7/2010. Diretrizes Curriculares Nacionais Gerais para a Educação Básica. Parecer homologado. Brasília: Diário Oficial da União, 9 de julho de 2010 , Seção 1, p. 10.

BRASIL. Lei $n^{\circ} 11.769$, de 18 de agosto de 2008. Altera a Lei $n^{\circ} 9.394$, de 20 de dezembro de 1996, Lei de Diretrizes e Bases da Educação, para dispor sobre a obrigatoriedade do ensino da música na educação básica. Diário Oficial da União, Brasília, n. 159, seção 1, p. 1, 19 ago. 2008.

DAYRELL, Juarez. A escola "faz" as juventudes? Reflexões em torno da socialização juvenil. Educ. Soc., Campinas, vol. 28, n. 100 - Especial, p. 1105-1128, out. 2007

DEL-BEN, Luciana. Educação musical escolar como objeto de estudo no Brasil: uma análise dos artigos da Revista da Abem. In: CONGRESSO DA ASSOCIAÇÃO BRASILEIRA DE EDUCAÇÃO MUSICAL, 2011, Vitória. Anais... Vitória: Abem, 2011. p. 1-11 (CD ROM).

DUSSEL, Inés. A transmissão cultural assediada: metamorfoses da cultura comum na escola1. Cadernos de Pesquisa, v. 39, n. 137, p. 351-365, maio/ago. 2009.

GONZÁLEZ, Fernando Jaime; FENSTERSEIFER, Paulo Evaldo. Entre o "não mais" e o "ainda não": pensando saídas do não-lugar da EF escolar I. Cadernos de Formação RBCE, p. 9-24, set. 2009.

KUENZER, Acacia Zeneida. O ensino médio no plano nacional de educação 20112020: superando a década perdida? Educ. Soc., Campinas, v. 31, n. 112, p. 851 873, jul.-set. 2010.

MOREIRA, Antonio Flávio Barbosa; CANDAU, Vera Maria. Currículo, conhecimento e cultura. In: BEAUCHAMP, J.; PAGEL, S. D.; NASCIMENTO, A. R. 
(Orgs.). Indagações sobre currículo: currículo, conhecimento e cultura. Brasília: Ministério da Educação, Secretaria de Educação Básica, 2007. Disponível em: $<$ http://portal.mec.gov.br/seb/arquivos/pdf/Ensfund/indag3.pdf>, Acesso em: 26 jun. 2011.

NÓVOA, António. A escola e a cidadania - apontamentos incómodos. 2011. Disponível em <http://biblioteca.universia.net/html_bura/ficha/params/id/ 49369693.html> Acesso em 26 fev. 2011.

SANTOS, Cristina Bertoni dos. Aula de música e escola: concepções e expectativas de alunos do ensino médio sobre a aula de música da escola. Revista da ABEM, v. 20.n. 27, p. 79-92, jan./jun. 2012.

SANTOS, Cristina Bertoni dos. Aula de música e escola: concepções e expectativas de alunos do ensino médio. 2009. Dissertação (Mestrado em música), Instituto de Artes, Universidade Federal do Rio Grande do Sul.

SOUZA, Jusamara. (Org.). Aprender e ensinar música no cotidiano. Porto Alegre: Sulina, 2008.

SOUZA, Jusamara. (Org.). Música, cotidiano e educação. Porto Alegre: Programa de Pós-Graduação em Música do Instituto de Artes da UFRGS, 2000.

ZIBAS, Dagmar M. L. A reforma do ensino médio nos anos de 1990: o parto da montanha e as novas perspectivas. Revista Brasileira de Educação, n. 28, p. 24-36, Jan./Fev./Mar./Abr. 2005. 